Cell Research (2003); 13(1):29-34

http://www.cell-research.com

\title{
Ohmefentanyl stereoisomers induce changes of CREB phosphorylation in hippocampus of mice in conditioned place preference paradigm
}

\author{
Can GAO ${ }^{1,2}$, Li Wei CHEN $^{1}$, Jie CHEN $^{1}$, Xue Jun XU ${ }^{1}$, Zhi Qiang CHI ${ }^{1, *}$ \\ ${ }^{1}$ Second Department of Pharmacology, Shanghai Institute of Materia Medica, Shanghai Institutes \\ for Biological Sciences, Chinese Academy of Sciences, Shanghai 200031, China \\ ${ }^{2}$ Research Center for Biochemistry and Molecular Biology, Xuzhou Medical College, Xuzhou, Jiangsu 221002, \\ China
}

\begin{abstract}
The present study was designed to determine the changes of phosphorylation of cAMP- response element binding protein (CREB) in hippocampus induced by ohmefentanyl stereoisomers (F9202 and F9204) in conditioned place preference (CPP) paradigm. The results showed that mice receiving F9202 and F9204 displayed obvious CPP. They could all significantly stimulate CREB phosphorylation and maintained for a long time without affecting total CREB protein levels. The effect of F9204 was similar to morphine which effect was more potent and longer than F9202. We also examined the effects of ketamine, a noncompetitive N-mthyl-D-aspartate receptor (NR) antagonist, on morphine-, F9202- and F9204- induced CPP and phosphorylation of CREB in hippocampus. Ketamine could suppress not only the place preference but also the phosphorylation of CREB produced by morphine, F9202 and F9204. These findings suggest that alterations in the phosphorylation of CREB be relevant to opiates signaling and the development of opiates dependence. NR antagonists may interfere with opiates dependence and may have potential therapeutic implications.
\end{abstract}

Key words: $c A M P$-response element binding protein (CREB), ohmefentanyl stereo isomers, opiates, hippocampus, conditioned place preference (CPP).

\section{INTRODUCTION}

Opiates addiction extracts enormous human and financial costs on society. Once formed, addiction can be a life-long condition in which individuals show intense drug craving and increased risk for relapse after years and even decades of abstinence[1],[2]. The mechanisms that underlie the development of opiates dependence remain unclear. Recently, the molecular pathways of learning and memory on the one hand, and of drug addiction on the other hand, have

\footnotetext{
* Corresponding author: Prof. Zhi Qiang CHI

Second Department of Pharmacology, Shanghai Institute of Materia Medica, Shanghai Institutes for Biological Sciences, Chinese Academy of Sciences, 294 Taiyuan Road, Shanghai 200031, China Tel: 86-21-64311833 ext 513, Fax: 86-21-64370269,

E-mail: zqchi@mail.shcnc.ac.cn

Received Oct-13-2002 Revised Dec-9-2002 Accepted Dec-13-2002
}

converged[3]. Learning and memory and drug addiction share certain intracellular signaling cascades, and depend on activation of the transcription factor cAMP- response element binding protein (CREB). They are accompanied by alterations in neural plasticity at glutamate synapses. Drug addiction is an aberrant form of learning, mediated by maladaptive recruitment of certain memory systems in the brain[4],[5]. There is evidence that relapses among drug-addicted humans also involve associative learning. This suggests that addiction involves extremely stable changes which are responsible for these long-lasting behavioral abnormalities in the brain. Regulation of gene expression is one mechanism that should lead to relatively stable changes within neurons[1]. CREB, a transcription factor in particular has been implicated in opiates 
addiction[1],[6],[7].

CREB is a transcription factor that binds to cAMP-response element in the promotor region of target genes and modulates their expression[8]. Phosphorylation of Ser133 within the kinase-inducible transcriptional activation domain of CREB is required to induce the transcriptional activity of the protein. CREB has been strongly implicated in memory formation in a wide range of species[9]. CREB has also been shown to play a key role in opiates dependence[10-14]. It may be an important molecular basis of craving and relapse.

Over the last several years, significant progress has been made in our understanding of the interactions between opioid and glutamate receptors in the neural mechanisms of opioid analgesia, tolerance, dependence, and withdrawal[15-19]. Considerable evidence implicates N-Methyl-D-aspartate receptor (NR) in the development of opiates tolerance and dependence. Agents that are NR antagonists may interfere with the development, maintenance and expression of the pathophysiological processes common to all drug abuse and may have potential therapeutic implications[20].

Ohmefentanyl(N-[1-(2-hydroxy-2-phenylethyl)3-methyl-4-peperidyl]-N-phenylo ropanamide, OMF) is a novel and potent analgesic agent with high affinity for $\mu$ opioid receptor[21,22]. Among the 8 stereo isomers of OMF (F9201-F9208), F9202 ((-)cis- (3R, 4S, 2' R) OMF) and F9204 ((+)-cis- (3R, $4 \mathrm{~S}, 2$ ' S) $\mathrm{OMF}$ ) had similarly potent analgesic action and high selectivity for $\mathrm{m}$ opioid receptor, but showed big difference in physical dependence[23]. Compound F9204 displayed a weak physical dependent potency. The effect of F9202 and F9204 on psychological dependence should be further investigated.

In the present study, we investigated both the rewarding effect using the conditioned place preference (CPP) paradigm (a criteria of psychological dependence) in mice and phosphorylation of CREB in hippocampus induced by F9202, F9204 and morphine. We also demonstrated the effect of ketamine, a noncompetitive NR receptor antagonist, in order to find some mechanisms of opiates dependence.

\section{MATERIALS AND METHODS}

\section{Animals}

Kunming strain male mice (ZKD-005) weighing 18-22g were supplied by the Animal Center, Shanghai Medical College of Fudan University. Animals were housed in plastic cages with food and water and maintained on a 12 - $\mathrm{h}$ light-dark cycle. Room temperature was maintained at $22 \pm 1^{\circ} \mathrm{C}$.

\section{Chemical reagents}

Ohmefentanyl stereoisomers (synthesized by the Chemical Group, $2^{\text {nd }}$ Department of Pharmacology, Shanghai Institute of Materia Medica, Chinese Academy of Sciences); morphine $\mathrm{HCl}$ (Qinghai Pharmaceutical LTD, China); ketamine hydrochloride (Shanghai $1^{\text {st }}$ Pharmaceutical LTD, China); anti-CREB and antiP-CREB (Ser133) monoclonal antibody (Sigma); anti-rabbit-IgG (Rockland); ECL detection kit (Amersham Co.).

\section{Conditioned place preference}

The induction and tests of the conditioned place preference (a model for psychological dependence ) were performed as described previously[19]. Briefly, the experiment consisted of preconditioning, conditioning and post-conditioning phases. The preconditioning phase (3 days) included one session of adaptive free investigation of both white and black compartments of placepreference box during $30 \mathrm{~min}$. On the second and third day, mice were placed in the box for $15 \mathrm{~min}$ and were allowed to explore both compartments freely once daily. Only animals preferring the dark compartment (spending 480-660s) were chosen for further studies. The mean time spent in the white and black compartments was recorded.

The conditioning phase consisted of ten 30-min sessions, and conducted twice a day for 5 consecutive days. The animals were confined to one compartment of the shuttle box with the door closed. On each day, the mouse was treated drugs (saline, $10 \mathrm{ml} /$ $\mathrm{kg}$ s.c.; morphine, $10 \mathrm{mg} / \mathrm{kg}$ s.c.; F9202, $18 \mu \mathrm{g} / \mathrm{kg}$ s.c.; F9204, 2.5 $\mu \mathrm{g} / \mathrm{kg}$ s.c.) according to ED95 analgesic dose respectively, and placed into the white compartment, and then received the saline (10 ml/kg s.c.) 6 hours later and was confined to the black compartment. The alternate vehicle and drug pairings occurred daily during 5 days. During the test phase, 15-min post-conditioning tests were conducted $24 \mathrm{~h}$ after the last conditioning session. The animals in a drug-free state were placed in the shuttle box with doors opened for $15 \mathrm{~min}$. The time spent in white compartments was recorded. Ketamine $(10 \mathrm{mg} / \mathrm{kg}$ i.p.) was injected $30 \mathrm{~min}$ before drugs treatment.

\section{Western blotting analysis}

For Western blotting analysis, mice were sacrificed immediately after recording. Hippocampus was then put into liquid nitrogen. The hippocampus was homogenized and sonicated in ice-cold lysis buffer ( $50 \mathrm{mM}$ Tris, $\mathrm{pH} 7.4 ; 150 \mathrm{mM} \mathrm{NaCl} ; 0$. $5 \%$ NP-40; 50 mM NaF; 1 mM Na3VO4; 5 mM EDTA; 50 mM NaPPi; $1 \mathrm{mM}$ DTT; $1 \mathrm{mM}$ PMSF; $5 \mathrm{mg} / \mathrm{ml}$ leupeptin; $2 \mathrm{mg} / \mathrm{ml}$ aprotinin ). The lysate was centrifuged at $13,000 \mathrm{~g}$ for $10 \mathrm{~min}$ at $4 \mathrm{oC}$ and the concentration of protein in each sample was determined using Lowry method with BSA as standard. Samples with equal amounts of protein were then separated 
by $10 \%$ polyacrylamide gel electrophoresis. Protein bands were electrically transferred to nitrocellulose membranes. The blots were blocked for $1 \mathrm{~h}$ in TBST buffer (20 m M Tris, $\mathrm{pH} 7.4 ; 137 \mathrm{mM}$ $\mathrm{NaCl} ; 0.1 \%$ Tween 20 ) with $5 \%$ nonfat milk at room temperature and then were incubated with monoclonal rabbit anti-pCREB (1: 1000) or -CREB (1:1000) antibodies at 4oC overnight. After being washed for three times with TBST, the blots were incubated with horseradish peroxidase conjugated anti-rabbit secondary antibody (1:5000) for $1 \mathrm{~h}$ at room temperature. The washings were repeated, and the blots were developed by enhanced chemiluminescence method and visualized by exposure to GS-800 Calibrated Densitometer (Bio-Rad).

\section{Statistical analysis}

All values were expressed as means \pm SE. Statistical significance was determined by one-way analysis of variance (ANOVA) followed by Dunnett's test. $\mathrm{P}$ values $<0.05$ were considered significant.

\section{RESULTS}

\section{Difference of CPP induced by F9202 and F9204 in mice}

To compare the difference of CPP between F9202 and F9204, the CPP was tested for these mice on post-conditioning day 1, 3 and 7 (day 1, day 3 and day 7). These results showed that animals receiving F9202 and F9204 displayed obvious CPP on day1 and day3 after the last training compared with saline group. These were indicated by a significant increase in the time spent in the drug-paired

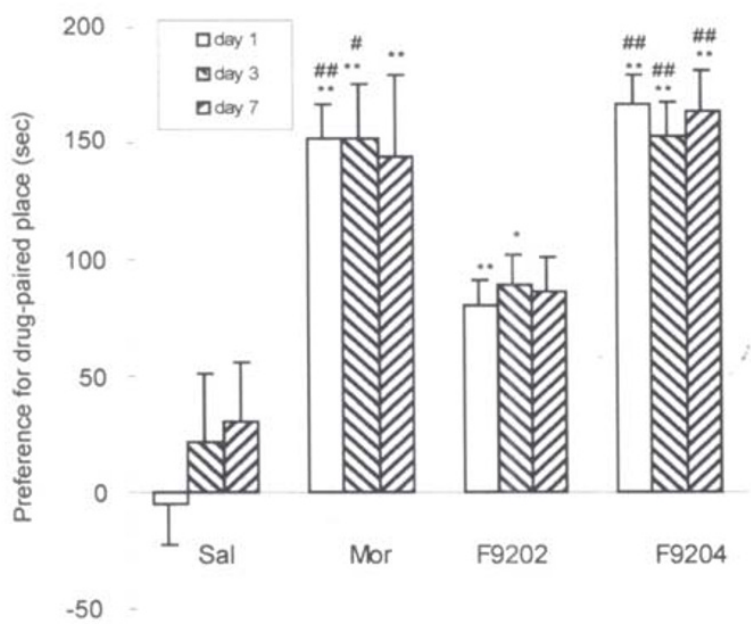

Fig 1. Conditioned place preference induced by saline (Sal), morphine (Mor) and OMF (F9202 and F9204). The time spent in drug-paired place was measured on 1, 3 or 7 days after the last training. Values are expressed as means $\pm \mathrm{SE}$ of 8-15 mice. $* \mathrm{P}<0.05, * * \mathrm{P}<0.01$ vs corresponding saline group; ${ }^{\#} \mathrm{P}<0.05,{ }^{\# \#} \mathrm{P}<0.01$ vs corresponding $\mathrm{F} 9202$ group. compartment. While the potency and duration of F9204 effect was longer than that of F9202. The effect of F9204 was similar to morphine (Fig 1).

Enhancement of CREB phosphorylation in hippocampus of opioid CPP mice

We attempted to find out whether morphine,
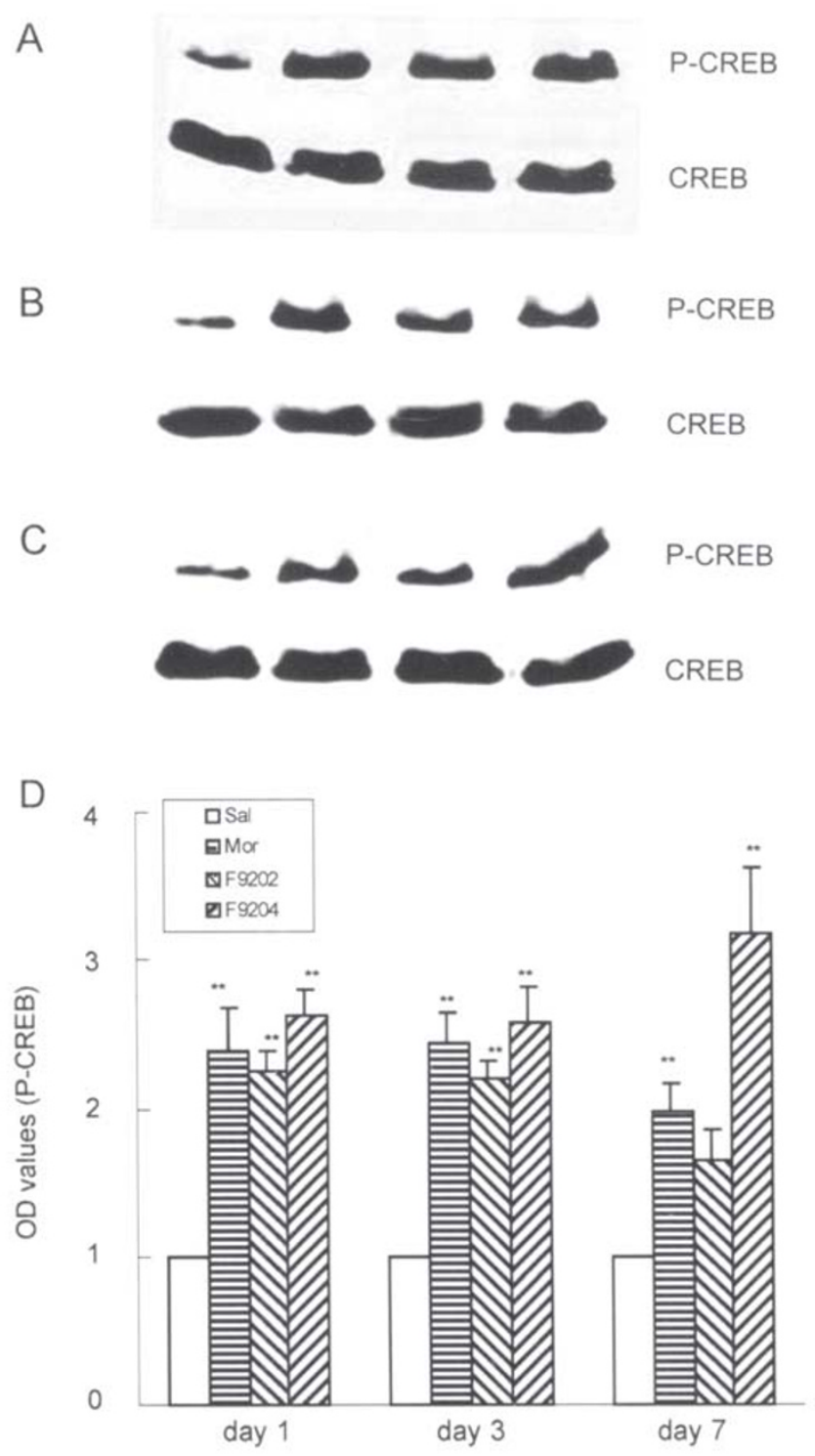

Fig 2. Detection of P-CREB activity in hippocampus of CPP mice induced by saline (Sal), morphine (Mor) and OMF (F9202 and F9204) on 1, 3 and 7 days (A, B and C) after the last training by Western blotting analysis and densitometry data (D). Values are expressed as meanss \pm SE of at least 3 experiments. ${ }^{* *} \mathrm{P}<0.01$ vs corresponding saline group. 


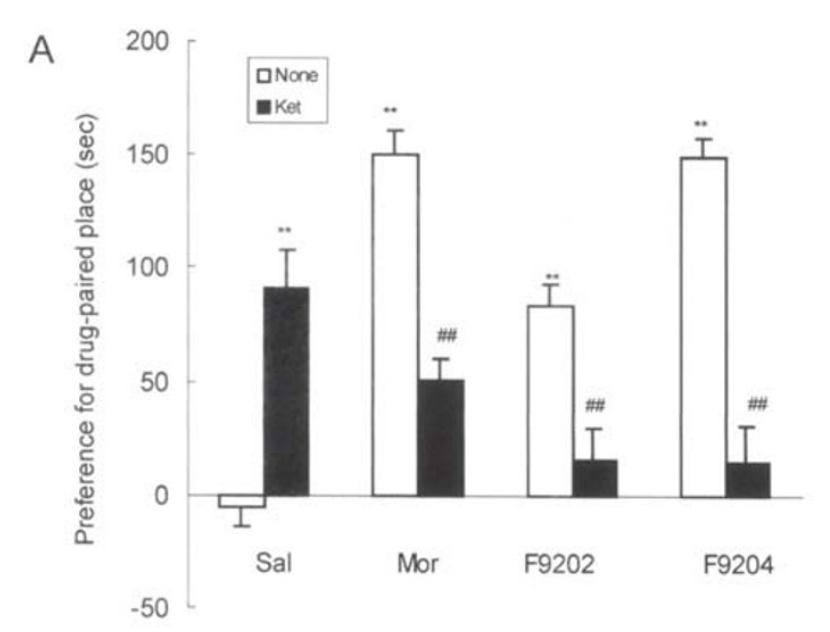

B
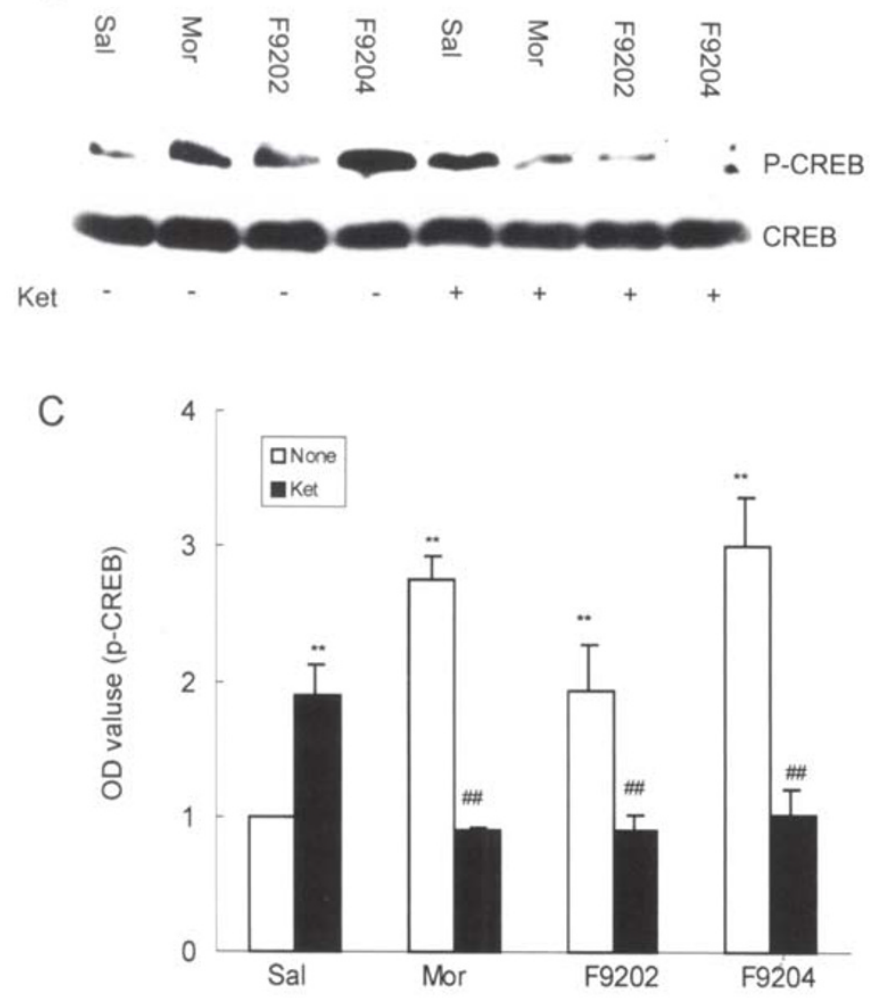

Fig 3. Effects of preadministration with ketamine ( Ket) on opioid-CPP (A), Western blotting of P-CREB levels (B) and densitometry data of P-CREB (C). Values are expressed as means \pm SE of 8-10 mice in CPP paradigm and at least 3 experiments in detecting P-CREB levels. **p $<0.01$ vs corresponding saline group. ${ }^{\# \#} \mathrm{P}<0.01$ vs corresponding noneketamine preadministration group.

F9202 and F9204 triggered CREB Ser133 phosphorylation in hippocampus of CPP mice. The mice were sacrificed immediately after being recorded during a 15 min test on post-conditioning day 1, 3 and 7 . The results demonstrated that morphine, F9202 and F9204 could all significantly stimulate CREB phosphorylation and maintained for a long time (Fig 2 ). The effect of F9204 was longer than that of F9202. In contrast, an immunoblot analysis with anti-CREB antiserum showed no change in the total CREB protein levels.

Effect of ketamine on opiates-induced CPP and CREB phosphorylation

To investigate the effects of ketamine, a NR antagonist, on the morphine and OMF induced CPP, ketamine $(10 \mathrm{mg} / \mathrm{kg})$ was preadministrated $30 \mathrm{~min}$ prior to each drug injection and then the mice were confined to the drug-paired compartment. One day after the last training, the time spent in drug-paired side for each mouse was measured during a $15 \mathrm{~min}$ test. The hippocampus was then excised for the Western blotting analysis. In the present results, ketamine itself produced a significant place preference. However, it can significantly inhibit morphine, F9202 and F9204-induced CPP (Fig 3A). The Western blotting analysis which detected the phosphorylation of CREB was similar to the results of CPP ( Fig 3B, 3C).

\section{DISCUSSION}

The molecular mechanisms underlying opiates dependence is not fully understood. CREB was first implicated in drug addiction because its activation was a predictable consequence of upregulation of the cAMP pathway, one of the best established adaptations to drug abuse[6]. Mice with mutations in the CREB gene showed decreased development of opiate physical dependence, as indicated by an attenuated withdrawal syndrome after administration of an opioid receptor antagonist. These findings provided strong support for a role of CREB in opiate physical dependence. Recently Walters[10] demonstrated that the aversive properties of morphine were still present in CREB mutant mice despite a reduction of physical withdrawal. On the other hand, these mice did not respond to the reinforcing properties of morphine in a conditioned place preference paradigm. Recent studies have shown hippocampus playing a central role in tolerance, dependence, and 
withdrawal[24-26]. The present study demonstrates that morphine, F9202 and F9204 significantly stimulate CREB phosphorylation and maintain for a long time in hippocampus of CPP mice. CREB has been implicated in the formation of long-term memory and plays a central and highly conserved role in the production of protein synthesis-dependent long-term changes in the brain. Activation of the cAMP pathway and of CREB-mediated transcription in the hippocampus are related to learning, as well as to longterm potentiation (LTP)[9]. In fact, learning and memory has been suggested to play an important role in drug addiction[3],[5]. Several of the molecular and cellular adaptations involved in addiction are also implicated in models of learning and memory. A variety of different compounds that impair learning and memory can prevent opiates dependence.

The notion that glutamate plays an important role in drug addiction is an exciting and new idea[3]. Recent studies have demonstrated that mice and rats treated with dizocilpine or memantine, another NR antagonist, combined with morphine showed neither the morphine nor NR antagonist-induced place preference[17]. It is proposed that NR antagonists may have multiple functions in treating addiction, including attenuation of withdrawal effects, normalization of the affective changes following initiation of abstinence which arise from neurochemical changes resulting from chronic addiction, and an attenuation of conditioned responses arising from drug-related stimuli[20]. As we know that NR has been implicated in mechanisms of neural plasticity. Since classical conditioning involves associative learning, it should also be dependent on neural plasticity. In the present study, we found for the first time that ketamine, a non competitive NR antagonist, was able to block ohmefentanyl-induced place preference and CREB phosphorylation in hippocampus. The results of this study fit well into the picture that substances which block the function of the NR complex impair plastic processes, resulting in an attenuation of place conditioning. This suggests that learning of morphine- and ohmefentanyl -induced reward would require activation of NR. One of morphine's actions is to inhibit GABAergic interneurons in the ventral tegmental area (VTA), which in turn leads to a disinhibition of dopaminergic neurons projecting from the VTA to the nucleus accumbens (NAc)[2],[5]. These neurons play a very important role in mediating the rewarding effects of a whole range of drugs of abuse. Ketamine itself could also induce CPP in mice and increase the phosphorylation of CREB in hippocampus. One possible explanation is that ketamine could indirectly activate the mesolimbic dopaminergic system through the blockade of the $\mathrm{NR}$, resulting in the production of the rewarding effect[4],[5]. Several experiments have also found that CGP-37849 and MK-801, other NR antagonists, were able to induce CPP[16], [27].

In the present results, the phosphorylation of CREB in hippocampus of CPP mice increased significantly during the post-conditioning day for a long time. The effect of F9204 was similar to morphine which effect was more potent and longer than that of F9202. Ohmefentanyl which is the most potent analgesic so far[28], has 8 isomers (F9201-F9208). F9202 and F9204 had similarly potent analgesic action, but showed a large difference in physical dependence[23]. Compound F9204 displayed a strong analgesic action and weak physical dependent potency. The present results indicate that there are a little difference in CPP paradigm between F9202 and F9204. The signal transduction of ohmefentanyl stereoisomers dependence should be further investigated.

In conclusion, the present findings provide evidence for the morphine- and ohmefentanyl isomers -induced CREB activation in hippocampus of CPP mice. The antagonist of NR can reduce these effects. These data indicate that the phosphorylation of CREB may be associated with stable changes in the brain that are responsible for long-lived behavioural abnormalities. NR antagonists may have multiple functions in treating dependence.

\section{REFERENCES}

[1] Nestler EJ. Molecular basis of long-term plasticity underlying addiction. Nat Rev Neurosci 2001; 2:119-28.

[2] Wise RA. Drug-activation of brain reward pathways. Drug Alcohol Depend 1998; 51:13-22.

[3] Nestler EJ. Total recall-the memory of addiction. Science 2001; 292:2266-7.

[4] Robbins TW, Everiff BJ. Drug addiction: bad habits add up. Nature 1999; 398:567-70.

[5] Berke JD, Hyman SE. Addiction, dopamine, and the molecular mechanisms of memory. Neuron 2000; 25:51532.

[6] Hyman SE. Shaking out the cause of addiction. Science 
1996; 273:611-12.

[7] Nestler EJ, Hope BT, Widnell KL. Drug addiction: a model for the molecular basis of neural plasticity. Neuron 1993; 11:995-1006.

[8] Xu J, Zhu JD, Ni M, et al. The ATF/CREB site is the key element for transcription of the human RNA methyltransferase like 1 (RNMTL1) gene, a newly discovered 17p13.3 gene. Cell Res 2002; 12:177-97.

[9] Deisseroth K, Bito H, Tsien RW. Signaling from synapse to nucleus: postsynaptic CREB phosphorylation during multiple forms of hippocampal synaptic plasticity. Neuron 1996; 16:89-101.

[10] Walters CL, Blendy JA. Different requirements for cAMP response element binding protein in positve and negative reinforcing properties of drugs of abuse. J Neurosci 2001; 21:9438-44.

[11] Shaw-Lutchman TZ, Barrot M, Wallace T, et al. Regional and cellular mapping of cAMP response element mediated transcription during naltrexone-precipitated morphine withdrawal. J Neurosci 2002; 22:3663-72.

[12] Guitart X, Thompson MA, Mirante CK, et al. Regulation of cyclic AMP response element-binding protein (CREB) phosphorylation by acute and chronic morphine in the rat locus coeruleus. J Neurochem 1992; 58:1168-71.

[13] Lane-Ladd SB, Pineda J, Boundy VA, et al. CREB (cAMP response element-binding protein) in the locus coeruleus: biochemical, physiological, and behavioral evidence for a role in opiate dependence. J Neurosci 1997; 17:7890901.

[14] Vanderschuren LJMJ, Vries TJD, Wardeh G, et al. A single exposure to morphine induces long-lasting behavioural and neurochemical sensitization in rats. Eur J Neurosci 2001; 14:1533-8.

[15] Wickelgren I. Teaching the brain to take drugs. Science 1998; 280:2045-7.

[16] Tzschentke TM, Schmidt WJ. N-Methyl-D-aspartic acidreceptor antagonists block morphine-induced conditioned place preference in rats. Neurosci Lett 1995; 193: 37-40.

[17] Scheggi S, Mangiavacchi S, Masi F, et al. Dizoclpine infusion has a different effect in the development of morphine and cocaine sensitization: behavioral and neurochemical aspects. Neurosci 2002; 109:267-74.

[18] Suzuki T, Kato H, Aoki, T et al. Effects of the non- competive NMDA receptor antagonist ketamine on morphine-induced place preference in mice. Life Sci 2000; 67:383-9.

[19] Suzuki T, Funada M, Misawa M, et al. Morphine-induced place preference conditioning in the CXBK mouse: characteristics of mu opioid receptor subtypes. Brain Res 1993; 602:45-52.

[20] Bisaga A, Popik P. In search of a new pharmacological treatment for drug and alcohol addiction: N-Methyl-Daspartate (NMDA)antagonists. Drug Alcohol Depen 2000; 59:1-15.

[21] Brine GA, Carroll FI, Richardsonleibert TM. Ohmefentanyl and its stereoisomers: chemistry and pharmacology. Curr Med Chem 1997; 4:247-70.

[22] Wang ZX, Zhu YC, Jin WQ, et al. Stereoisomers of N-[1(2-hydroxy-2-phenylethyl)-3-methyl-4-peperidyl]-Nphenyloropanamide: synthesis, stereochemistry, analgesic activity, and opioid receptor binding characteristics. J Med Chem 1995; 38:3652-9.

[23] Guo GW, He Y, Jin WQ, et al. Comparison of physical dependence of ohmefentanyl stereoisomers in mice. Life Sci 2000; 67:113-20.

[24] Fan GH, Wang LZ, Qiu HC, et al. Inhibition of calcium/ calmodulin-dependent protein kinase II in rat hippocampus attenuates morphine tolerance and dependence. Mol Pharmacol 1999; 56:39-45.

[25] Lu L, Zeng SS, Liu DH, et al. Inhibition of the amygdala and hippocampal calcium/calmodulin-dependent protein kinase II attenuates the dependence and relapse to morphine differently in rats. Neurosci Lett 2000; 291:1915.

[26] Lou LG, Zhou TH, Wang P, et al. Modulation of Ca2+/ Calmodulin-dependent protein kinase II activity by acute and chronic morphine administration in rat hippocampus: differential regulation of $\mathrm{a}$ and $\mathrm{b}$ isoforms. Mol Pharmacol 1999; 55:557-63.

[27] Layer RT, Kaddis FG, Wallace LJ. The NMDA receptor antagonist MK-801 elicits conditioned place preference in rats. Pharmacol Biochem Behav 1993; 44:245-7.

[28] Wei Q, Zhou DH, Shen QX, et al. Human mu-opioid receptor overexpressed in Sf9 insect cells functionally coupled to endogenous Gi/o proteins. Cell Res 2000; 10: 93-102. 